\title{
Adjunctive treatment with moxonidine versus nitrendipine for hypertensive patients with advanced renal failure: a cost-effectiveness analysis
}

\author{
Kavi J Littlewood*1, Wolfgang Greiner ${ }^{2}$, Dominique Baum ${ }^{3}$ and \\ York Zoellner ${ }^{3}$
}

Address: ${ }^{1}$ Mapi Values Netherlands BV, Houten, The Netherlands, ${ }^{2}$ Universität Bielefeld, Fakultät für Gesundheitswissenschaften, Bielefeld, Germany and ${ }^{3}$ Solvay Pharmaceuticals GmbH, Hannover, Germany

Email: Kavi J Littlewood* - kavi.littlewood@mapivalues.com; Wolfgang Greiner - wolfgang.greiner@uni-bielefeld.de;

Dominique Baum - d.baum@solvay.com; York Zoellner - york.zoelner@solvay.com

* Corresponding author

Published: 24 July 2007

BMC Nephrology 2007, 8:9 doi:10.1 I86/147|-2369-8-9

This article is available from: http://www.biomedcentral.com/I47I-2369/8/9

(c) 2007 Littlewood et al; licensee BioMed Central Ltd.

This is an Open Access article distributed under the terms of the Creative Commons Attribution License (http://creativecommons.org/licenses/by/2.0), which permits unrestricted use, distribution, and reproduction in any medium, provided the original work is properly cited.

\begin{abstract}
Background: Systemic hypertension often accompanies chronic renal failure and can accelerate its progression to endstage renal disease (ESRD). Adjunctive moxonidine appeared to have benefits versus adjunctive nitrendipine, in a randomised double-blind six-month trial in hypertensive patients with advanced renal failure. To understand the longer term effects and costs of moxonidine, a decision analytic model was developed and a cost-effectiveness analysis performed.

Methods: A Markov model was used to extrapolate results from the trial over three years. All patients started in a nonESRD state. After each cycle, patients with a glomerular filtration rate below $15 \mathrm{ml} / \mathrm{min}$ had progressed to an ESRD state.

The cost-effectiveness analysis was based on the Dutch healthcare perspective. The main outcome measure was incremental cost per life-year gained. The percentage of patients progressing to ESRD and cumulative costs were also compared after three years. In the base case analysis, all patients with ESRD received dialysis.
\end{abstract}

Results: The model predicted that after three years, $38.9 \%(95 \% \mathrm{Cl} 31.8-45.8)$ of patients treated with nitrendipine progressed to ESRD compared to $7.5 \%(95 \% \mathrm{Cl} 3.5-12.7)$ of patients treated with moxonidine. Treatment with standard antihypertensive therapy and adjunctive moxonidine was predicted to reduce the number of ESRD cases by $81 \%$ over three years compared to adjunctive nitrendipine.

The cumulative costs per patient were significantly lower in the moxonidine group $€ 9,858(95 \% \mathrm{Cl} 5,50 \mathrm{I}-16,174)$ than in the nitrendipine group $€ 37,472$ (95\% Cl 27,957-49,478).

The model showed moxonidine to be dominant compared to nitrendipine, increasing life-years lived by $0.044(95 \% \mathrm{Cl}$ $0.020-0.070)$ years and at a cost-saving of $€ 27,615(95 \% \mathrm{Cl} 16,894-39,583)$ per patient.

Probabilistic analyses confirmed that the moxonidine strategy was dominant over nitrendipine in over $98.9 \%$ of cases. The cumulative 3-year costs and LYL continued to favour the moxonidine strategy in all sensitivity analyses performed.

Conclusion: Treatment with standard antihypertensive therapy and adjunctive moxonidine in hypertensive patients with advanced renal failure was predicted to reduce the number of new ESRD cases over three years compared to adjunctive nitrendipine. The model showed that adjunctive moxonidine could increase life-years lived and provide long term cost savings. 


\section{Background}

End-stage renal disease (ESRD) is a disorder that occurs worldwide and is associated with a high cost to society due to the need for dialysis or renal transplantation. In 1994, 7,340 patients in the Netherlands were receiving renal replacement therapy, incurring direct medical costs of NLG 584 million (262 million $1994 €$ ) and indirect costs of NLG 3.5 million (1.6 million $1994 €$ ). De Wit et al estimated that in 2003, there would be 11,500 patients receiving renal replacement therapy at a cost to society of over NLG 900 million (405 million $1994 €$ ) [1].

Systemic hypertension frequently accompanies chronic renal failure (CRF) and is a strong risk factor for the development of ESRD [2]. Thus current drugs target systemic hypertension in addition to proteinuria in an attempt to slow the progression of renal disease [3]. Angiotensinconverting enzyme inhibitors (ACEI) or angiotensin receptor blockers $(\mathrm{ARB})$ are the treatment of choice for hypertensive patients with CRF, with the addition of diuretics for inadequate blood pressure control. Patients often require athird drug to control hypertension effectively $[4,5]$.

Moxonidine may be a good candidate for adjunctive treatment to standard therapy as it interferes with the sympathetic nervous system overactivity [6] which may contribute to hypertension in CRF patients [6-9].

The short term benefits of adjunctive treatment with moxonidine on top of standard antihypertensive therapy have been shown, versus adjunctive nitrendipine, in a single randomised double-blind 24-week trial in hypertensive patients with advanced renal failure. Most patients received standard therapy of ACEI or ARB plus diuretics. Although this study was primarily a safety and tolerability study, a significant difference was seen in creatinine clearance decline between the moxonidine group and the comparator group after 24 weeks of treatment [10]. This was the only study found comparing moxonidine to nitrendipine in a review of the literature to date. Creatinine clearance is an indicator of the glomerular filtration rate of the kidneys. A reduction in creatinine clearance levels indicates a decline in kidney function. The trial measured baseline proteinuria in around $60 \%$ of patients in each group and found levels were similar across both groups. But proteinuria levels were not available in $40 \%$ of patients and therefore it is not possible to know this impact on the overall trial outcomes, as proteinuria is a risk factor for renal disease progression. Therefore a major assumption of our study was that the differences in creatinine clearance decline were not caused by other risk factors (such as underlying disease or proteinuria level). Based on this assumption, it was hypothesised that adjunctive moxonidine in hypertensive patients with renal failure may contribute to decreasing the burden of ESRD.

In order to understand the effects of moxonidine on renal progression and on costs over a longer period, a decision analytic model was developed and a cost-effectiveness analysis was performed on the basis of the Dutch healthcare setting.

\section{Methods}

\section{Decision-Analytic Model and assumptions}

A Markov model was built in MS Excel to extrapolate results from the six-month trial, of adjunctive moxonidine versus adjunctive nitrendipine, over three years (or six cycles of six months). This time horizon of three years closely approximates the maximum follow-up period of cohorts of ESRD patients found in the literature [11-14]. In the model, all patients started in a non-ESRD state (NESRD). NESRD was defined as patients with advanced renal failure and hypertension, with a glomerular filtration rate (GFR) above $15 \mathrm{ml} / \mathrm{min}$, not treated with dialysis or transplant. After each cycle of six months, patients with a GFR below $15 \mathrm{ml} / \mathrm{min}$ were considered to have progressed to the ESRD state. This cut-off value of $15 \mathrm{ml} / \mathrm{min}$ was based on the European Renal Association (ERA) guidelines [15] and US National Kidney Foundation guidelines [16]. Once in the ESRD state, patients could not go back to the NESRD state, they could either remain in this state or progress to death. (Figure 1)

Creatinine clearance measures from the trial were not measured directly, but were obtained using the Cockcroft \& Gault equation, and assumed to equal GFR measures in the model. The Cockcroft-Gault equation is frequently

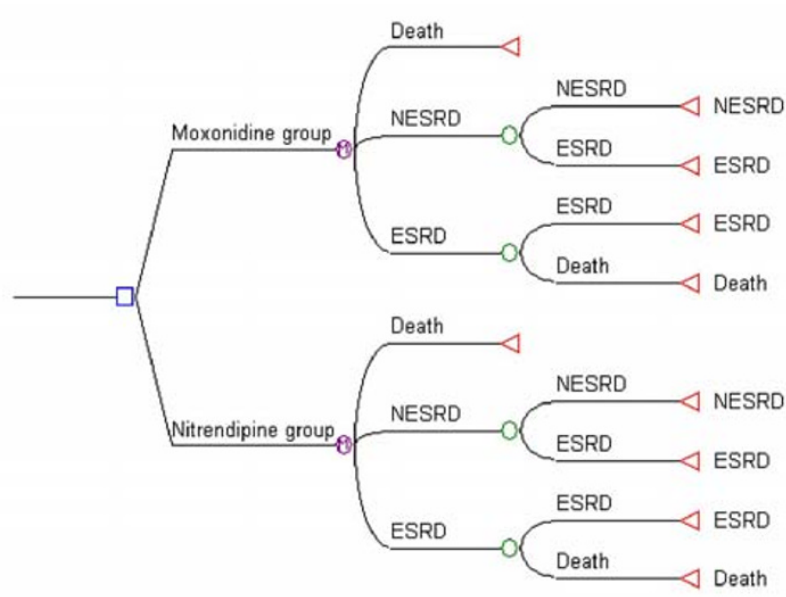

\section{Figure I}

The Decision analytic model. Legend $\square$ Decision node M Markov node $\bigcirc$ Choice node $\triangleleft$ Terminal node 
used for estimating GFR in adults. Although it was originally developed for estimating creatinine clearance, it has been widely tested as a good predictor of GFR [17]. Age, gender, and body weight are used to correct for the differences in muscle mass, and hence creatinine generation rate.

\section{Transition probabilities}

Transition probabilities for moving from the NESRD (GFR $>15 \mathrm{ml} / \mathrm{min}$ ) to ESRD (GFR $<15 \mathrm{ml} / \mathrm{min}$ ) state were based on extrapolations of the trial results. The average GFR decline over the three year time horizon was assumed to be linear. A linear progression was judged to be acceptable in these very renally-impaired patients. The mean decline in GFR over the trial period - from baseline (visit 2) to week 24 (visit 9) - was $0.7 \mathrm{ml} / \mathrm{min}$ for the moxonidine group and $1.8 \mathrm{ml} / \mathrm{min}$ for the nitrendipine group. This average decline over a six-month period was applied to each six-month period in the model, with accompanying standard deviations (SD) keeping the ratio of mean/ $\mathrm{SD}$ constant throughout the cycles. Based on the given and estimated means and SD, the percentage of patients with ESRD (GFR $<15 \mathrm{ml} / \mathrm{min}$ ) was then calculated for each six-month period using the gamma distribution (parameters Moxonidine $\alpha=1.445, \beta=83.555$, Nitrendipine: $\alpha=12.403, \beta=66.597$ ). The gamma distribution was found to best describe the trial data compared to the normal or lognormal distribution (skewed to the right with no negative values) $[18,19]$. A consequence of this method is that there were some patients with ESRD at baseline in both groups, and these patients were not receiving dialysis or transplants. Therefore only new cases of ESRD were used to derive transition probabilities for the model.

For each six-month period: Transition probability $=$ new cases ESRD/NESRD population (Table 1.)

Transition probabilities for moving from the ESRD state to Death were based on Dutch mortality rates for patients on dialysis and transplanted patients. The base case model assumed all patients were on dialysis. As survival rates were very different for ESRD patients on dialysis or receiving transplants, the percentage of patients on each of these types of renal replacement therapy had to be varied in sensitivity analyses[20]. (Table 1.)

\section{Summary of assumptions}

- A time horizon of 3 years approximates the maximum follow-up period of ESRD patients

- The difference in GFR decline found in the trial was not caused by differences in other risk factors for decline in renal function (like underlying disease or proteinuria level).

- The Cockroft and Gault formula is acceptable to calculate the GFR levels for the population of the study.

- The average decline in GFR over the years can be described by a linear function

- Extrapolating the average decline found over the initial 6 months will not overestimate the decline in the following periods.

- The gamma distribution is best to estimate the percentage of patients with a GFR $<15$.

- All patients received dialysis during the ESRD state.

- From the NESRD state patients could stay in this state or enter the ESRD state

- From the ERSD state patients could stay in this state or enter the death state but they could not go back to the NESRD state.

\section{Resource use and costs by health state}

Costs per cycle for the NESRD state included general medical costs (consultations, diagnostics and laboratory services) based on costing data from the economic evaluation

Table I: Transition probabilities of moving from NESRD state to ESRD state

\begin{tabular}{|c|c|c|c|c|c|c|c|}
\hline \multirow[t]{2}{*}{ Cycle } & \multicolumn{2}{|c|}{ NESRD to ESRD $\dagger$} & \multirow{2}{*}{$\begin{array}{c}\text { NESRD to Deatht† } \\
\text { all-cause }\end{array}$} & \multicolumn{4}{|c|}{ ESRD to Death ${ }^{\ddagger}$} \\
\hline & moxonidine & nitrendipine & & Dialysis & Transplant & Dial/Trans 64\%/34\% & Dial/Trans $50 \% / 50 \%$ \\
\hline I & 0.019 & 0.077 & 0.0042 & 0.067 & 0.013 & 0.048 & 0.040 \\
\hline 2 & 0.012 & 0.053 & 0.0042 & 0.067 & 0.013 & 0.048 & 0.040 \\
\hline 3 & 0.013 & 0.069 & 0.0042 & 0.067 & 0.013 & 0.048 & 0.040 \\
\hline 4 & 0.014 & 0.089 & 0.0042 & 0.067 & 0.013 & 0.048 & 0.040 \\
\hline 5 & 0.016 & 0.118 & 0.0042 & 0.067 & 0.013 & 0.048 & 0.040 \\
\hline 6 & 0.017 & 0.157 & 0.0042 & 0.067 & 0.013 & 0.048 & 0.040 \\
\hline
\end{tabular}

tBased on data from Vonend et al 2003.

ttBased on Dutch all-cause mortality 2005 (8.4 per I,000 inhabitants), (Centraal Bureau voor de Statistiek)

‡Based on data from ERA EDTA Annual report 2002. 
of benazepril for Dutch CRF patients [21], and drug usage from the trial (moxonidine, nitrendipine and an average cost of hypertension drugs used) [10]. Diuretic drug costs were assumed to be covered in the general medical costs. The ESRD state costs per cycle included costs for dialysis or transplantation, consultations, general drug, diagnostic and laboratory services costs based on the economic evaluation of ESRD treatments in the Netherlands performed by the Wit et al[22]. Costs associated with entering the state Death were based on costs for patients in the terminal phase of ESRD reported by van Hout et al [21]. (Table 2.)

All cost data were expressed in Euros; USD costs were converted to Euro by purchasing power parities [23]. All costs were transformed to 2004 prices by means of price indexes from the Dutch "Manual for cost calculations: methods and recommend prices for economic evaluations in health care." All drug costs were based on public prices (ex VAT) from the Dutch Z-index. The daily defined dosage was used to calculate the drug price per cycle.

Generally Markov models assume transitions from one health state to the next occur at the end of the cycle, however in reality this transition can occur at any point during the cycle, therefore a half-cycle correction was incorporated.

\section{The cost-effectiveness analysis}

The cost-effectiveness analysis was based on the Dutch healthcare perspective, with a time horizon of three years from the start of treatment. The main outcome measure was the incremental cost per life-year gained. The percentage of patients with ESRD and the cumulative costs were also compared at three years. A discount rate of $4 \%$ on costs and $1.5 \%$ on life-years per annum was applied, as recommended by the Dutch guidelines [24].

The cost-effectiveness analysis was performed for a hypothetical cohort of patients similar to the patients in the trial: adult patients with advanced renal failure (GFR $<30$ $\mathrm{ml} / \mathrm{min}$ ) and hypertension (DBP 80-100). Patients were already receiving treatment with loop diuretics and ACEI or $\mathrm{ARB}$, and were given moxonidine $(0.3 \mathrm{mg} / \mathrm{day})$ or nitrendipine $(20 \mathrm{mg} /$ day $)$. Patient exclusion criteria included presence of sick sinus syndrome, higher degree sino-atrial or atrioventricular block, bradycardia, malignant arrhythmia, heart failure of New York Heart Association stage III or IV, severe chronic ischemic heart disease, symptomatic cerebrovascular disease, unstable angina pectoris, severe hepatic disease, history of malignant disease within two years, pregnancy or lactation, history of depression, drug abuse or alcoholism.

\section{Scenario Analyses}

In the base case analysis, all patients with ESRD were assumed to receive dialysis treatment, a discount rate was applied to costs and benefits, a linear decline was assumed for progression to ESRD and no patients died from the NESRD state. Scenario analyses were performed to evaluate the effects and costs if:

- $64 \%$ of patients received dialysis treatment and 36\% received a transplant (split based on the incidence figures of the Dutch Renine Registry for 2002 [20])

- or $50 \%$ of patients received dialysis and $50 \%$ received a transplant (split based on prevalence figures from the Dutch Renine Registry 2002 [20])

Both analyses were performed with a 'living donor to cadaver donor' ratio of $34 \%$ to $66 \%$ [20].

- $0 \%$ discount on costs and benefits was applied

- an exponential decline was used for progression to ESRD

- all-cause Dutch death rate was applied to patients with NESRD

Table 2: Breakdown of costs $(€)$ by health state.

\begin{tabular}{|c|c|c|c|c|}
\hline Cost components per cycle (6-months) & NESRD & $\begin{array}{l}\text { ESRD First } 2 \\
\text { cycles }\end{array}$ & $\begin{array}{c}\text { ESRD Subsequent } \\
\text { cycles }\end{array}$ & $\begin{array}{c}\text { Termina } \\
\text { ESRD }\end{array}$ \\
\hline moxonidine $0.3 \mathrm{mg} / \mathrm{d}^{\dagger}$ & 82.80 & - & - & - \\
\hline nitrendipine $20 \mathrm{mg} / \mathrm{d}^{\dagger}$ & 74.40 & - & - & - \\
\hline Other antihypertensives ${ }^{\dagger}$ & 93.90 & - & - & - \\
\hline Consultations, diagnostics, laboratory services, diuretics $\ddagger$ & 213.00 & - & - & - \\
\hline Dialysis including consultations, drugs, diagnostics and laboratory services* & - & $34,522.00$ & $32,627.00$ & - \\
\hline Transplantation including consultations, drugs, diagnostics and laboratory services* & - & $22,850.00$ & $4,570.00$ & - \\
\hline Terminal ESRD care $\ddagger$ & - & - & - & $1,4 \mid 6.00$ \\
\hline
\end{tabular}

† z-index: Cost of antihypertensives based on patient usage: $89 \%$ on ACE I (ddd enalapril $25 \mathrm{mg}$ ) and I I\% on ARB (ddd losartan $50 \mathrm{mg}$ ), and $35.6 \%$ on beta blocker (ddd atenolol $75 \mathrm{mg}$ ) and $27.4 \%$ on alpha blocker (ddd doxazosin $4 \mathrm{mg}$ ). Costs of diuretics were assumed to be included in NESRD costs based on manuscript van Hout et al.

$\ddagger$ van Hout et al

$*$ de Wit et al 


\section{Probabilistic sensitivity analyses}

The source data are characterised by uncertainty. A probabilistic sensitivity analysis was performed to quantify the uncertainty in the model outcomes. A random value was repeatedly sampled from distributions reflecting the uncertainty level of the input source data, plugged into the model, and then the outcome of the model was calculated. Each model outcome is presented with a point estimate along with uncertainty reflected by the 2.5 th and 97.5th percentile of the uncertainty distribution. Uncertainty in the transition probabilities from NESRD to ESRD were based on the trial and expressed with beta distributions (alpha and beta determined from the standard error). Uncertainty in resource data were expressed with triangular distributions, with the low and high values as $80 \%$ and $120 \%$ of the expected value. Probabilistic sensitivity analysis was performed for both the base case scenario and for scenario analyses.

\section{Results}

\section{Effects}

The model predicted that after three years, 38.9\% (95\%CI 31.8-45.8) of patients treated with nitrendipine progressed to ESRD compared to only $7.5 \%$ (95\%CI 3.512.7) of patients treated with moxonidine. Thus suggesting that standard treatment with adjunctive moxonidine could prevent $31.4 \%$ of new cases of ESRD compared to adjunctive nitrendipine (see Figure 2.), or reduce the number of ESRD cases by $81 \%$.

The proportion of survivors was $98.6 \%$ in the moxonidine group after three years compared to $93.9 \%$ in the nitrendipine group. Thus the model suggests that patients treated with moxonidine could gain on average 0.044 (95\%CI 0.020-0.070) life-years compared to patients on

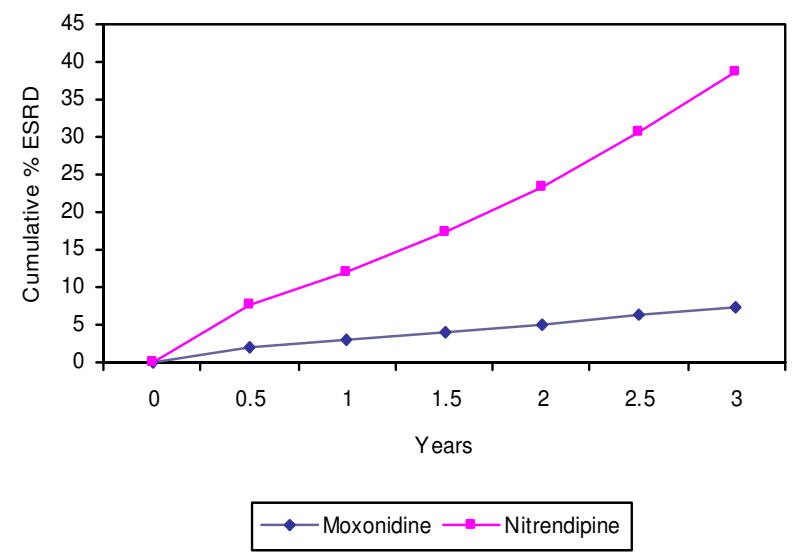

Figure 2

Cumulative percent of patients with ESRD after 3 years. nitrendipine (discounted life-years were 2.950 (95\% CI 2.937-2.959) versus 2.907 (95\%CI 2.882-2.927).

\section{Costs}

After three years, the cumulative costs per patient appeared to be lower in the moxonidine group (€9,858 with 95\% CI 5,501-16,174) than in the nitrendipine group (€37,472 with $95 \%$ CI $27,957-49,478)$ (see Figure $3)$. Thus moxonidine provided a cost saving of $€ 27,615$ (95\%CI 16,894-39,583).

\section{Cost-effectiveness}

The model calculated that moxonidine treatment provided a cost saving of $€ 27,615$ (95\%CI 16,894-39,583) and extra life-years gained of 0.044 (with $95 \%$ CI $0.020-$ 0.070 ) years compared to nitrendipine treatment, thus moxonidine was the dominant strategy. (Table 3) Moxonidine is said to be dominant because it could provide a more effective treatment strategy and for less cost. Probabilistic sensitivity analyses confirmed that the moxonidine strategy was dominant over nitrendipine in over $98.9 \%$ of cases.

\section{Costs and impact of treatment}

Thus if 100 patients were given each treatment over three years, the model predicts that after three years 7 patients on moxonidine versus 39 on nitrendipine will have progressed to ESRD, and 1 patient will have died in the moxonidine arm versus 6 in the nitrendipine arm. The cost of treating the moxonidine group would be $€ 985,800$ versus $€ 3,747,200$ for the nitrendipine group, due to the high cost of treating patients who have progressed to ESRD.

\section{Scenario analyses}

The proportion of ESRD patients receiving dialysis or transplantations was varied in sensitivity analyses. The

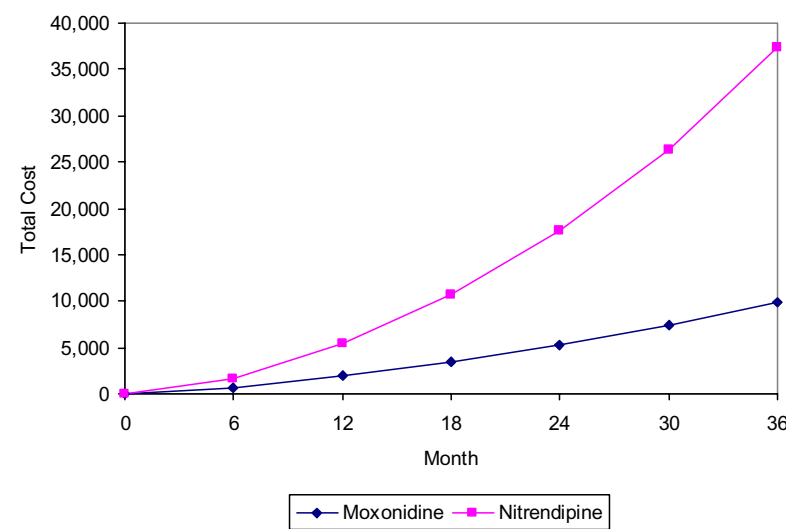

Figure 3

Expected 3-year cumulative cost per patient. 
Table 3: Results of the base case model after 3 years

\begin{tabular}{lccc}
\hline & \% progress to ESRD $(95 \% \mathrm{Cl})$ & Life years lived $(95 \% \mathrm{Cl})$ & Costs $(€)(95 \% \mathrm{Cl})$ \\
\hline Moxonidine & $7.5 \%(3.5-12.7)$ & $2.950(2.937-2.959)$ & $€ 9,858(5,50 \mathrm{I}-16,174)$ \\
Nitrendipine & $38.9 \%(31.8-45.8)$ & $2.907(2.882-2.927)$ & $€ 37,472(27,957-49,478)$ \\
\hline
\end{tabular}

model showed that when $64 \%$ of patients received dialysis (and 34\% received transplantations), the cumulative 3year costs remained lower with moxonidine versus nitrendipine ( $€ 8,496$ (95\% CI 4,920-13,367) versus $€ 31,035$ (95\% CI 23,618-40,163) respectively), and life-years remained higher in the moxonidine arm 2.954 (95\% CI 2.944-2.960) versus 2.923 (95\% CI 2.907-2.936) respectively). When $50 \%$ of patients received dialysis (and 50\% transplantation), the cumulative 3-year costs and LYL continued to favour the moxonidine strategy versus nitrendipine (€7,953 (95\% CI 4,603-12,546) and 2.955 (95\%CI 2.946-2.960) for moxonidine versus $€ 28,649$ (95\% CI 21,938-36,392) and 2.929 (95\% CI 2.9152.941) for nitrendipine).

When a $0 \%$ discount rate was applied to costs and effects the following results were found: Cumulative costs were $€ 10,349$ (95\%CI 5,572-17,282) with moxonidine and $€ 39,035$ (95\% CI 29,324-50,003) with nitrendipine, resulting in a cost saving of $€ 28,686$ (95\% CI $17,772-$ $41,347)$ with moxonidine. Life-years lived were 2.987 (95\% CI 2.971-2.996) for moxonidine and 2.943 (95\% CI 2.919-2.963) for nitrendipine, resulting in 0.044 (95\% CI 0.019-0.070) life-years gained with moxonidine.

When the average GFR decline was assumed to decrease exponentially, the results still supported moxonidine over nitrendipine; all patients on nitrendipine had progressed to ESRD after 2 years versus $25 \%$ of patients on moxonidine (or $74 \%$ after 3 years). Thus moxonidine would provide 0.084 (95\%CI 0.059-0.108) additional life-years at a cost saving of $€ 48,364$ (95\%CI 37,966-59,198) after 3 years.

When Dutch all-cause mortality was incorporated to the NESRD arm, the life-years gained with moxonidine was $0.041(95 \% \mathrm{CI}-0.035-0.112)$ years at a cost saving of $€ 27,252$ (95\%CI 16,652-38,854). Moxonidine was dominant in $90 \%$ of cases.

\section{Discussion}

With this model, moxonidine treatment on top of standard therapy in severely renally-impaired patients appears to be cost-effective versus adjunctive nitrendipine, resulting in lower treatment costs $(€ 27,615$ lower $(95 \% \mathrm{CI}$ $16,894-39,583)$ ) and a greater number of life-years lived 0.044 (with 95\% CI 0.020-0.070) when the results of the six month trial are extrapolated over three years. Sensitivity analyses have shown that these results are robust. Thus given the assumptions of the model, we can conclude that moxonidine could delay progression to ESRD in a large number of patients, thereby reducing the numbers of patients requiring dialysis or transplants compared to standard treatment with adjunctive nitrendipine. Treatment with moxonidine could therefore contribute to reducing the economic burden of ESRD and allow patients to live longer in a non-ESRD state.

\section{Limitations of the model}

Data used in the model was taken from the only study available at the time of moxonidine versus nitrendipine, which was a six-month trial, in 171 patients, with proteinuria levels measured in 103 patients. In the trial, creatinine clearance was calculated using the Cockcroft \& Gault equation. As creatinine clearance is the result of clearance due to GFR and secretion of creatinine in the tubules, the model assumed that both treatments had no effect on secretion, thus GFR was equated to creatinine clearance measures alone.

The difference in GFR decline in the trial was assumed not to be due to differences in risk factors for renal progression such as level of proteinuria like albuminuria. Data on albuminuria were only available for a subset of patients in the trial (52/89 moxonidine patients and 51/82 nitrendipine patients). These data showed no significant differences between groups, although mean and median albuminuria values were lower in the moxonidine group $(1.3 \pm 1.8 ; 0.8$ versus $1.9 \pm 2.1 ; 1.1$ at baseline $)$. A limitation of this study is that the missing data for the remaining patients may mean that the two groups were not well matched for albuminuria, a major prognostic factor for renal decline [10].

The average GFR decline over the three year time horizon was assumed to be linear. This is not uncommon in the literature [25-27]. The extrapolation of GFR values from the six month trial also implied that the decline in the first three months after starting treatment was not significantly different than the decline in the following periods, as is sometimes suggested in the literature [18]. However some clinicians assume an exponential decline over time. If the decline is exponential, and disease progression occurs faster, the benefit of moxonidine will be even greater as it appears to delay progression compared to nitrendipine. 
The results of the scenario analysis show that all nitrendipine patients would have progressed to ESRD compared to $25 \%$ of moxonidine patients after two years.

The model only included direct costs. The addition of indirect costs would however be expected to increase the benefit seen with moxonidine, as patients remain in a better state of health for longer and are therefore able to be more productive.

Patients with ESRD are presumed to have much worse quality of life than patients at earlier stages of the disease. Utility values found in the literature report measures of 0.41 for patients on kidney dialysis [28] compared to 0.60 for patients with chronic renal failure [29]. A higher utility value is associated with a better state of health. As such, a cost-utility analysis would be expected to produce even better results for moxonidine compared to standard treatment with nitrendipine, as patients treated with moxonidine remained in a non-ESRD state for longer.

Adjunctive treatment with moxonidine was assumed to have a renoprotective effect occurring independently of blood pressure control in the six month trial. This effect may be supported by the results of a recent study in which moxonidine was the only factor that significantly reduced the risk of a decrease of $50 \%$ or more in creatinine clearance rate, or the need for dialysis, or death, in patients following renal transplant. The relative risk reduction due to moxonidine was 0.3 (95\% CI 0.1 - 0.6) in the multivariate analysis [30]. Results of a small study in the Netherlands may also support the benefits of adjunctive moxonidine in chronic renal failure. In this study, moxonidine normalised sympathetic hyperactivity, which plays a role in renal hypertension, in patients on chronic eprosartan treatment [19].

\section{Conclusion}

The model extrapolated results from a 6-month trial over three years. Treatment with standard antihypertensive therapy (ACE inhibitor or ARB and loop diuretics) and adjunctive moxonidine in hypertensive patients with advanced renal failure was predicted to reduce the number of ESRD cases by $81 \%$ over three years compared to adjunctive nitrendipine. The model showed moxonidine to be dominant compared to nitrendipine, increasing life-years lived by 0.044 (95\%CI $0.020-0.070)$ years and at a cost-saving of $€ 27,615$ (95\%CI 16,894-39,583) per patient.

\section{Competing interests}

This study was sponsored by Solvay Pharmaceuticals GmbH, Hannover, Germany.

\section{Authors' contributions}

$\mathrm{KL}, \mathrm{YZ}$ and DB contributed to the design of the study, data collection and analysis. KL and WG contributed to the drafting and reviewing of the manuscript. All authors read and approved the final manuscript.

\section{Acknowledgements}

The authors are grateful to Professor Dr. Reiner Leidl (University of Munich), for commenting on an earlier version of this manuscript

\section{References}

I. De Wit GA, Polder IJ, Jager KJ, De Charro FTh: De maatschappelijke kosten van nierziekten in Nederland. TSG 200I, 79:49-54.

2. Klag MJ, Whelton PK, Randall BL, Neaton JD, Brancati FL, Ford CE, Shulman NB, Stamler J: Blood pressure and end-stage renal disease in men. N Engl J Med 334(I): I3-8. 1996 Jan 4

3. Yu HT: Progression of chronic renal failure. Arch Intern Med I63(12):1417-29. 2003 Jun 23

4. Epstein $M$, Tobe $S$ : What is the optimal strategy to intensify blood pressure control and prevent progression off renal failure. Curr Hypertens Rep 200I, 3(5):422-8.

5. Schwenger, Ritz E: Audit of antihypertensive treatment in patients with renal failure. Nephrol Dial Transplant 1998, I3(I 2):309|-5.

6. Rump LC: The role of sympathetic nervous activity in chronic renal failure. Journal of Clinical and Basic Cardiology 200I, 4(3): $179-182$

7. Preston RA, Singer I, Epstein M: Renal parenchymal hypertension: current concepts of pathogenesis and management. Arch Intern Med 156(6):602-II. I 996 Mar 25

8. Converse RL, Jacobson TN, Toto RD, Jost CM, Cosentino F, FouadTarazi F, Victor RG: Sympathetic overactivity in patients with chronic renal failure. N Engl J Med 1992, 327(27): $1912-8$.

9. Neumann J, Ligtenberg G, Oey L, Koomans H, Blankestijn PJ: Moxonidine normalizes sympathetic hyperactivity in patients with eprosartan-treated chronic renal failure. J Am Soc Nephrol 2004, I 5:2902-7.

10. Vonend O, Marsalek P, Russ H, Wulkow R, Oberhauser V, Rump LC: Moxonidine treatment of hypertensive patients with advanced renal failure. J Hypertens 2003, 21(9): 1709-17.

II. Ruggenenti P, Perna A, Gherardi G, Garini G, Zoccali C, Salvadori M, Scolari F, Schena FP, Remuzzi G: Renoprotective properties of ACE-inhibition in non-diabetic nephropathies with nonnephrotic proteinuria. Lancet 1999, 354:359-64.

12. The GISEN Group: Randomised placebo-controlled trial of effect of ramipril on decline in glomerular filtration rate and risk of terminal renal failure in proteinuric, non-diabetic nephropathy. Lancet 1997, 349: 1857-63.

13. Lewis EJ, Hunsicker LG, Clarke WR, Berl T, Pohl MA, Lewis JB, Ritz $E$, Atkins RC, Rohde R, Raz I: Renoprotective effect of the angiotensin-receptor antagonist irbesartan inpatients with nephropathy due to type 2 diabetes. N Engl J Med 200I, 345(I2):85I-60.

14. Giatras I, Lau J, Levey AS: Effect of angiotensin-converting enzyme inhibitors on the progression of nondiabetic renal disease: a meta-analysis of randomized trials. Ann Intern Med I27(5):337-45. 1997 Sep I

15. ERA Guideline 1.3: Measurement of renal function, when to refer and when to start dialysis. Nephrol Dial Transplant 2002, 17:10-11.

16. US National Kidney Foundation Dialysis Outcomes Quality Initiative (NKF/DOQI) [http://www.kidney.org/professionals/ kdoqi/index.cfm]. Accessed 25 July 2005

17. K/DOQI Clinical Practice Guidelines for Chronic Kidney Disease: Estimation of GFR. ERA guideline. Nephrol Dial Transplant 2002, I7(Suppl 7):7-15.

18. Fernández-Abascal H, Guijarro MM, Rojo JL, Sanz JA: Cálculo de probabilidades y Estadística. Ed. Ariel, Barcelona (Spain); 1994.

19. Johnson NL: Distributions in Statistics. In 1992, 1994, 1997. Copyright 200 I JL Rojo Volume I-4. J. Wiley y Houghton M. Co .

20. ERA EDTA Annual report 2002 [http://www.era-edta-reg.org/ files/annualreports/pdf/AnnRep2002.pdf]. Accessed 25 July 2005 
21. van Hout BA, Simeon GP, McDonnell J, Mann JF: Economic evaluation of benazepril in chronic renal insufficiency. Kidney Int Suppl 1997, 63:S159-62.

22. de Wit GA, Ramsteijn PG, de Charro FT: Economic evaluation of end stage renal disease treatment. Health Policy 1998, 44(3):215-32.

23. OECD [http://www.oecd.org]. Accessed 25 July 2005

24. Oostenbrink JB, Bouwmans CAM, Koopmanschap MA, Rutten FFH: Handleiding voor kostenonderzoek. Methoden en standaard kostprijzen voor economische evaluaties in de gezondheidszorg. College voor Zorgverzekeringen. Geactualiseerde versie 2004.

25. Klahr S, Levey AS, Beck GJ, Caggiula AW, Hunsicker L, Kusek JW, Striker G: The effects of dietary protein restriction and bloodpressure control on the progression of chronic renal disease. Modification of Diet in Renal Disease Study Group. N Engl J Med 330(1 3):877-84. I 994 Mar 3 |

26. Del Vecchio L, Locatelli F: The renoprotective effect of combined antihypertensive drugs. J Nephrol 200I, I 4(I):7-14.

27. Locatelli F, Del Vecchio L, D'Amico M, Andrulli S: Is it the agent or the blood pressure level that matters for renal protection in chronic nephropathies? J Am Soc Nephrol 2002, I3(Suppl 3):S|96-20|.

28. Kiberd BA: Should Hepatitis C-infected kidneys be transplanted in the United States? Transplantation 1994, 57(7): 1068-72.

29. Katz DA, Cronenwett JL: The cost-effectiveness of early surgery versus watchful waiting in the management of small abdominal aortic aneurysms. J Vasc S 1994, 19(6):980-90.

30. Radermacher J, Mengel M, Ellis S, Stuht S, Hiss M, Schwarz A, Eisenberger U, Burg M, Luft FC, Gwinner W, Haller $\mathrm{H}$ : The renal arterial resistance index and renal allograft survival. $N$ Engl J Med 349(2): I I5-24. 2003 Jul 10

\section{Pre-publication history}

The pre-publication history for this paper can be accessed here:

http://www.biomedcentral.com/1471-2369/8/9/prepub
Publish with Bio Med Central and every scientist can read your work free of charge

"BioMed Central will be the most significant development for disseminating the results of biomedical research in our lifetime. "

Sir Paul Nurse, Cancer Research UK

Your research papers will be:

- available free of charge to the entire biomedical community

- peer reviewed and published immediately upon acceptance

- cited in PubMed and archived on PubMed Central

- yours - you keep the copyright
BioMedcentral 